\title{
Effect of BSA Protein on the Contrast Properties of Magnetite Nanoparticles during MRI
}

\author{
O. Strbak ${ }^{a, *}$, M. Kubovcikova ${ }^{b}$, L. Baciak ${ }^{c}$, I. Khmara ${ }^{b}$, D. Gogola ${ }^{d}$, M. KonerackA ${ }^{b}$,

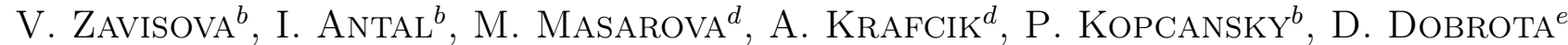 \\ AND I. FROLLO ${ }^{d}$ \\ ${ }^{a}$ Biomedical Center Martin, Jessenius Faculty of Medicine in Martin, Comenius University in Bratislava, \\ Mala Hora 4, 03601 Martin, Slovakia \\ ${ }^{b}$ Institute of Experimental Physics, SAS, Watsonova 47, 04001 Kosice, Slovakia \\ ${ }^{c}$ Faculty of Chemical and Food Technology, STU, Radlinskeho 9, 81237 Bratislava, Slovakia \\ ${ }^{d}$ Institute of Measurement Science, SAS, Dubravska cesta 9, 84104 Bratislava 4, Slovakia
}

${ }^{e}$ Department of Medical Biochemistry, Jessenius Faculty of Medicine in Martin, Comenius University in Bratislava,

Mala Hora 4, 03601 Martin, Slovakia

\begin{abstract}
The aim of the study was to establish whether there is a significant change in the MRI contrast of magnetite nanoparticles, after BSA protein binding on the surface of particles. The rationale is the applicability of this feature in clinical practice for the tracking of specific proteins which are often associated with various pathologies. Contrast agents could bind to this specific marker, with the change in MRI contrast indicating the presence of pathology. We found that changes in relative contrast acquired at low-field MRI offer potential for the differentiation of magnetite nanoparticles with and without BSA protein. However, the variations in the transverse relaxation time $\left(T_{2}\right)$ and transverse relaxivity $\left(r_{2}\right)$, acquired at high-field MRI, were too small to be applicable for biomedical applications.
\end{abstract}

DOI: 10.12693/APhysPolA.131.1102

PACS/topics: 87.61.-c, 75.75.Fk, 87.15.kp

\section{Introduction}

Currently, magnetic nanoparticles in combination with proteins are attracting significant interest in biomedical applications such as specific protein MRI contrast agents [1]. Changes in the concentration levels of proteins are associated with various pathological processes, and as such they can function as biomarkers of various diseases (e.g. cancer [2], neuroinflammation [3]). Magnetic nanoparticles, as a consequence of proton spins coupling with larger magnetic moments of nanoparticles, reduce the transverse relaxation time $\left(T_{2}\right)$, thus increasing the relaxivity of water [4]. Protein binding to the nanoparticle can potentially affect the coupling mechanism, changing the MRI signal and providing desired information regarding the presence of a biomarker. Therefore, the aim of this study was to determine the degree of the BSA protein's influence on the relative contrast and relaxivity of the magnetite nanoparticles stabilised by PEG, after binding to the particles. Quantification of such influence could facilitate the diagnostics of disorders associated with the presence of specific proteins.

\section{Materials and methods}

PEG-stabilised magnetite nanoparticles were prepared by the co-precipitation method of ferric and ferrous salts

*corresponding author; e-mail: oliver.strbak@centrum.cz in an alkaline aqueous medium, as described in [5]. Particles were made with and without (control) the BSA protein, and then diluted in such a way that each of the samples had half the concentration of the previous one, resulting in a concentration gradient from $3.8 \mathrm{mg} / \mathrm{ml}$ to $9.06 \times 10^{-7} \mathrm{mg} / \mathrm{ml}$.

MRI measurements were performed at two types of magnetic fields:

(i) Clinical $0.2 \mathrm{~T}$ system ESAOTE - images were acquired with standard $T_{2}$-weighted spin echo (SE) pulse sequence, repetition time $T R=1500 \mathrm{~ms}$, echo time $T E=50 \mathrm{~ms}$.

(ii) Experimental $4.7 \mathrm{~T}$ system VARIAN $-T_{2}$ was obtained spectroscopically by Car-Purcell-Meiboom-Gill (CPMG) echo pulse sequence.

For all the acquired samples the relative contrast (RC), transverse relaxivity $\left(r_{2}\right)$ and $T_{2}$ values were evaluated and compared.

The relative contrast is defined as follows:

$R C=\left(I-I_{0}\right) / I_{0}$,

where $I_{0}$ is the signal intensity without magnetite nanoparticles, and $I$ represents the signal intensity with magnetite nanoparticles.

The $r_{2}$ is calculated through

$$
R_{2}=r_{2} C+R_{2}^{0} \text {, }
$$

where $R_{2}^{0}$ is the transverse relaxation rate in the absence of nanoparticles, $R_{2}$ represents the transverse relaxation rate in the presence of nanoparticles, and $C$ is the nanoparticles' concentration. 
The differences in the relative contrast $\left(R C_{\text {diff }}\right)$ of the same samples, with and without BSA protein, were then evaluated as follows:

$$
R C_{\mathrm{diff}}=\left|R C_{\mathrm{BSA}(-)}-R C_{\mathrm{BSA}(+)}\right|,
$$

where $R C_{\mathrm{BSA}(-)}$ is the relative contrast of the magnetite nanoparticles without $\mathrm{BSA}$ protein, and $R C_{\mathrm{BSA}(+)}$ is the relative contrast of the magnetite nanoparticles with bound BSA protein.

The same process was also carried out for the $T_{2}$ in order to evaluate the $T_{2 \text { diff }}$.

\section{Results}

Figure 1 presents the relative contrast of magnetite nanoparticles with (green) and without (blue) BSA protein binding acquired at low-field system. Although not identical, the shape of the curves is very similar. It is obvious that in both cases the optimum contrast change interval lies between samples 6 and 11, which corresponds to the magnetite concentration of $3.71 \div 59.375 \mu \mathrm{g} / \mathrm{ml}$. For example, the recommended concentration of the MRI contrast agent Resovist is $\approx 97 \mu \mathrm{g} / \mathrm{ml}$. The higher concentrations (samples 1-5) were due to vast hypointensive artefacts being utterly undifferentiable. To the contrary of the negative contrast influence of iron oxide nanoparticles in the $T_{2}$-weighted MRI images, we observed an increase in the relative contrast value for samples $11-17$. This is likely to be caused by the prevailing longitudinal relaxation mechanism in lower particle concentrations. The magnetite concentration of $3.71 \mu \mathrm{g} / \mathrm{ml}$ apparently represents the critical point, where the transversal relaxation mechanism begins to dominate the longitudinal relaxation.

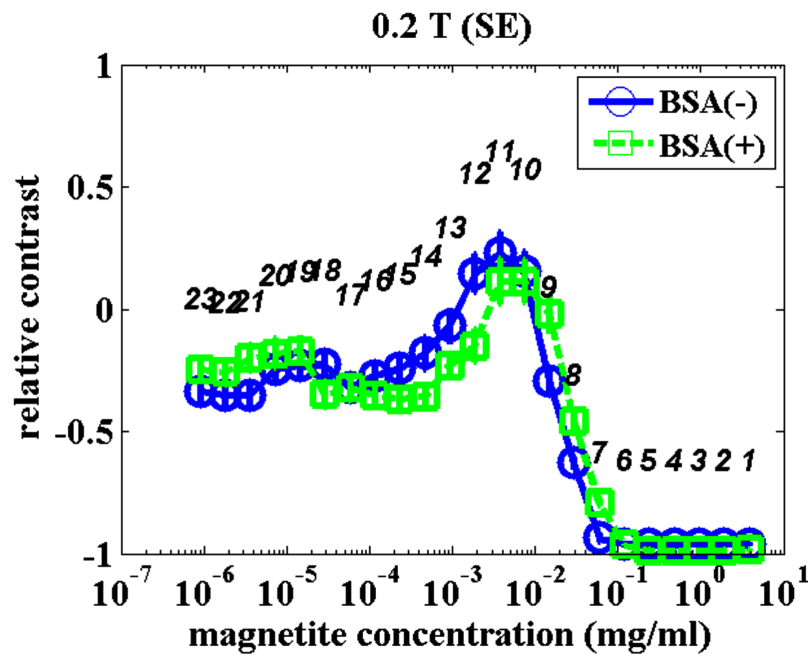

Fig. 1. Relative contrast of magnetite nanoparticles with (green line) and without (blue line) BSA protein binding, in comparison with magnetite concentration (logarithmic scale). Black ciphers represent the sample number. Data were acquired at $0.2 \mathrm{~T}$ with $T_{2}$-weighted SE pulse sequence.

The quantitative changes $\left(R C_{\text {diff }}\right)$ in the relative contrast of magnetite nanoparticles with and without the BSA protein in low-field system are shown in Fig. 2.

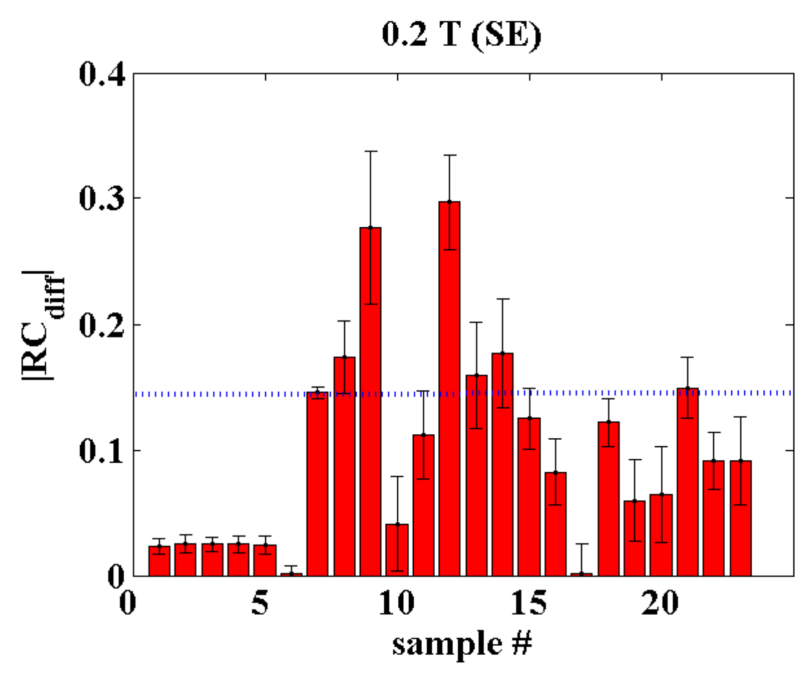

Fig. 2. Difference in relative contrast of magnetite nanoparticles with and without BSA protein binding, in comparison with magnetite concentration (sample number). Data were acquired at $0.2 \mathrm{~T}$ with $T_{2}$-weighted SE pulse sequence. Blue line represents the contrast change visible to the naked eye.

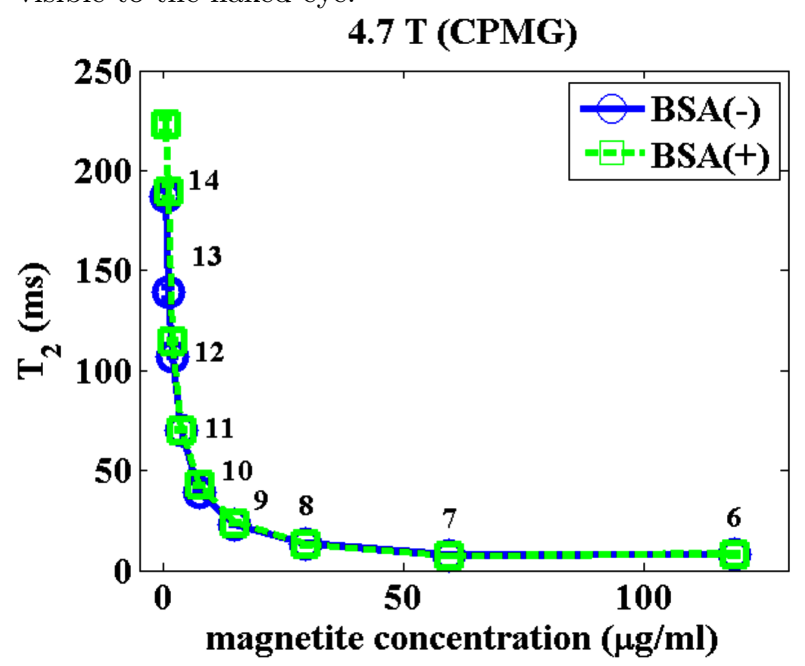

Fig. 3. $T_{2}$ of magnetite nanoparticles with (green line) and without (blue line) BSA protein binding, in comparison with magnetite concentration. Black ciphers represent the sample number. Data were acquired at $4.7 \mathrm{~T}$ with CPMG pulse sequence.

The blue line represents the contrast change visible to the naked eye in the low-field system $(\approx 15 \%)$. Five samples exceed this border $(8,9,12,13,14)$, although only two of them cross the $20 \%(9,12)$ threshold.

These results suggest that the relative contrast comparison of samples with and without protein binding is theoretically possible at low-field MRI, but only for magnetite concentrations ranging from 4 to $60 \mu \mathrm{g} / \mathrm{ml}$ (samples 11 and 7 ). This is due to the higher concentration levels forming the strong hypointensive artefacts, which disrupt the entire signal. On the other hand, in lower concentration levels we observed a prevailing longitudinal relaxation mechanism, which is not desired in $T_{2}$-weighted imaging. 
Based on the results at low-field MRI, we selected samples 6-14 for relaxivity measurements at high-field MRI. In Fig. 3 the $T_{2}$ is shown, acquired at $4.7 \mathrm{~T}$. We observed almost identical curve shapes for the samples with and without BSA protein, with maximal change in $T_{2}(14 \%)$ for concentrations around $1 \mu \mathrm{g} / \mathrm{ml}$ (Fig. 4). The results indicate that protein binding has only a faint effect on the $T_{2}$, when measured at high-field system. This is contrary to the relative contrast comparison at low-field MRI.

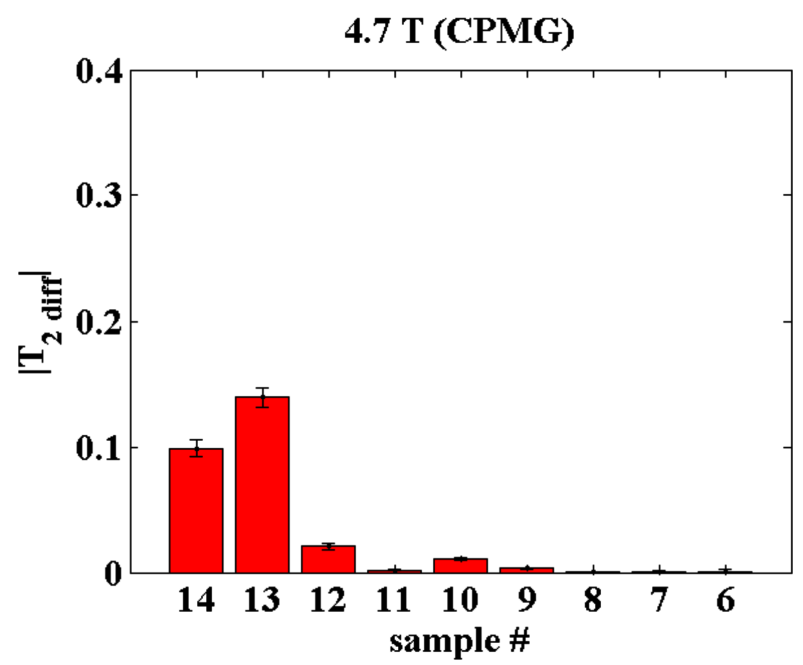

Fig. 4. Difference in $T_{2}$ of magnetite nanoparticles with and without BSA protein binding, in comparison with magnetite concentration (sample number). Data were acquired at $4.7 \mathrm{~T}$ with $\mathrm{CPMG}$ pulse sequence.

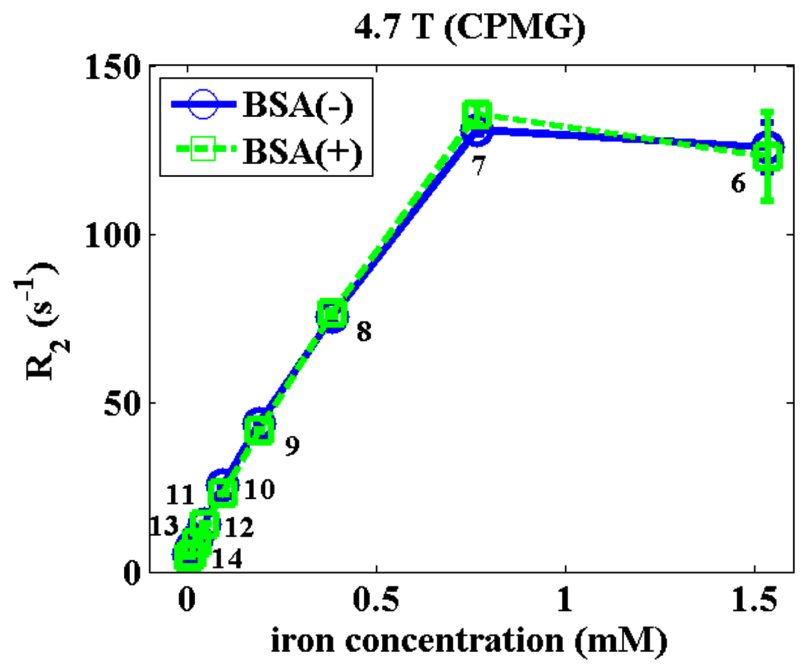

Fig. 5. Transverse relaxation rate $\left(R_{2}\right)$ of magnetite nanoparticles with (green line) and without (blue line) BSA protein binding, in comparison with magnetite concentration. Data were acquired at $4.7 \mathrm{~T}$ with $\mathrm{CPMG}$ pulse sequence.

The same concentration upper limit $(60 \mu \mathrm{g} / \mathrm{ml}$, sample 7) seen in the relative contrast comparison was also found in the transverse relaxation rate (Fig. 5). Therefore, only samples $7-14$ were used for the calculation of the $r_{2}$ values. We found the relaxivity of magnetite nanoparticles as follows:

- without BSA protein: $r_{2}^{\mathrm{BSA}(-)}=165.97 \pm 1.4(\mathrm{mM} \mathrm{s})^{-1}$,

- with BSA protein:

$$
r_{2}^{\mathrm{BSA}(+)}=173.57 \pm 3.2(\mathrm{mM} \mathrm{s})^{-1} \text {. }
$$

This agrees with typical $r_{2}$ values of small iron oxide nanoparticles - in the order of $100(\mathrm{mM} \mathrm{s})^{-1}[6]$. However, the difference between the $r_{2}$ of particles with and without BSA protein is too small to be applicable in biomedical applications. On the other hand, we used magnetite nanoparticles without specific adjustments, which could possibly increase the variance.

\section{Conclusions}

We showed that changes in the relative contrast of magnetite nanoparticles with and without BSA protein, and acquired at $0.2 \mathrm{~T}$, have potential in the differentiation of particles after binding to the protein. This could be helpful in the tracking of specific proteins (markers) associated with various pathologies. However, we did not observe the same variations in $T_{2}$ and $r_{2}$, acquired at $4.7 \mathrm{~T}$. In this case, the variations were too small to be applicable in clinical practice.

\section{Acknowledgments}

This work was supported through the Slovak Research and Development Agency, projects no. APVV-0431-12, APVV-15-0029, APVV-14-0120, APVV-14-0932 and the Slovak Scientific Grant Agency, projects no. VEGA $2 / 0013 / 14,2 / 0141 / 16,2 / 0045 / 13$, and by the project "Biomedical Center Martin" (ITMS code: 26220220187).

\section{References}

[1] S. Xue, H. Yang, J. Qiao, F. Pu, J. Jiang, K. Hubbard, K. Hekmatyar, J. Langley, M. Salarian, R.C. Long, R.G. Bryant, X.P. Hu, H.E. Grossniklaus, Z.-R. Liu, J. Yang, Proc. Natl. Acad. Sci. USA 112, 6607 (2015).

[2] A.K. Chan, D.C. Lockhart, W. von Bernstorff, R.A. Spanjaard, H.-G. Joo, T.J. Eberlein, P.S. Goedegebuure, Int. J. Cancer 82, 721 (1999).

[3] S. Yu, L. Zuo, F. Wang, Z.J. Chen, Y. Hu, Y.J. Wang, X.M. Wang, W. Zhang, BMC Neurol. 14, 113 (2014).

[4] B.A. Goins, W.T. Phillips, Nanoimaging, Pan Stanford Publ., Singapore 2011.

[5] V. Zavisova, M. Koneracka, J. Kovac, M. Kubovcikova, I. Antal, P. Kopcansky, M. Bednarikova, M. Muckova, J. Magn. Magn. Mater. 380, 85 (2015).

[6] N.L. Adolphi, K.S. Butler, D.M. Lovato, T.E. Tessier, J.E. Trujillo, H.J. Hathaway, D.L. Fegan, T.C. Monson, T.E. Stevens, D.L. Huber, J. Ramu, M.L. Milne, S.A. Altobelli, H.C. Bryant, R.S. Larson, E.R. Flynn, Contrast Media Mol. Imaging 7, 308 (2012). 